\title{
Music increases
}

Charles J. Cruise MD; FRCPC, Frances Chung MD, FRCPC, Suntheralingham Yogendran MD, FRCPC, D'Arcy Little MD satisfaction in elderly
outpatients undergoing

cataract surgery

Purpose: Music has long been known to reduce anxiety, minimize the need for sedatives, and make patients feel more at ease. The purpose of the study was to evaluate the effect of music in elderly outpatients undergoing elective cataract surgery with retrobulbar block and monitored anaesthetic care using fentanyl or alfentanil and midazolam.

Methods: One hundred and twenty one patients were prospectively and randomly assigned to hear: relaxing suggestions, white noise, operating room noise or relaxing music via audio-cassette headphones. Vital signs were documented before and after retrobulbar block and every 15 min thereafter. Anxiety was assessed using the State-Trait Anxiety Inventory (STA) before and after surgery. Visual analogue scales (VAS) were used to assess anxiety and patient satisfaction postoperatively with a standardized questionnaire. Between group comparisons were made using Chi-Square, or ANOVA, where appropriate.

Results: There were no differences between groups in STAl or anxiety VAS scores at any time. Differences were noted in systolic blood pressure, but not in other vital signs. Patients' ratings of the whole operative experience, satisfaction with the tape played, general level of relaxation and preference for the chosen tape for subsequent surgery were different (music $>$ relaxing suggestions $>$ white noise and $O R$ noise, $P<0.05$ ).

Conclusions: Elderly patients undergoing cataract surgery under retrobulbar block were more satisfied with their experience if they heard relaxing music, rather than relaxing suggestions or white noise or OR noise. The type of auditory stimuli to which the patients were exposed did not influence the level of anxiety.

Objectif : On sait depuis longtemps que la musique réduit l'anxiété, diminue le besoin de sédatifs, et procure du confort au patient. L'objectif de cette étude était d'évaluer l'influence de la musique chez des patients ágés opérés pour une cataracte en chirurgie ambulatoire réglée sous bloc rétrobulbaire associé à du fentanyl ou de l'alfentanil avec midazolam et sous surveillance anesthésique.

Méthodes : Cent vingt et un patients étaient prospectivement et aléatoirement assignés à entendre avec des écouteurs une vidéocassette qui transmettait un langage relaxant, le silence, les bruits d'une salle d'opération ou une musique reposante. Les signes vitaux étaient enregistrés avant et après le bloc rétrobulbaire et à toutes les 15 min par la suite. L'anxiété était évaluée sur l'inventaire des traits d'anxiété (STAl) avant et après la chirurgie. Une échelle visuelle analogue (EVA) servait à évaluer l'anxiété alors que le degré de satisfaction postopératoire était estimé sur un questionnaire standard. Les groupes étaient comparés avec le chi-carré ou l'ANOVA selon le cas.

Résultats : II n'a jamais eu de différences entre les groupes pour le STAl et à l'EVA. Quant aux signes vitaux, on n'a observé des différences que pour la pression artérielle systolique. L'évaluation de l'expérience chirurgicale par le patient, sa satisfaction de la bande magnétique écoutée, son degré de relaxation et sa préférence pour la bande qu'il choisirait pour une chirurgie à venir était différents (musique > langage relaxant>silence et bruits de la salle d'opération, $P<0,05$ ).

Conclusion : Des patients âgés soumis à une chirungie pour cataracte sous bloc rétrobulbaire ont été plus satisfaits de leur expérience s'ils entendaient de la musique reposante plutót qu'un langage relaxant, le silence ou les bruits d'une salle d'opération. 
$\mathrm{T}$

HE surgical experience is an anxiety-provoking event. Anaesthetists use various means to reduce this anxiety, including the preoperative interview, ${ }^{1}$ anxiolytic premedication, ${ }^{2}$ and the use of intraoperative sedatives and hypnotics to supplement local or regional anaesthesia for surgical procedures. ${ }^{3}$

Music reduces anxiety and discomfort. At the same time, there has been increasing concern over the use of music in the operating room, since it may contribute to the overall level of background noise and impair effective communication among members of the surgical team. ${ }^{4}$ Several studies attest to the usefulness of music in the surgical experience at allaying anxiety. ${ }^{5-9}$

The effect of music has not been assessed in the elderly patient undergoing cataract surgery. Since this is the commonest procedure performed in North America, ${ }^{10}$ it would be useful to ascertain whether this non-medicinal mode of anxiolysis is of benefit, especially since elderly patients do not tolerate sedatives as well as their younger counterparts, ${ }^{11}$ Elderly patients are often prescribed numerous medications, and they are more susceptible to potentially adverse drug interactions. ${ }^{12}$ It would be valuable to know if music reduced the need for sedatives in this patient population.

Therefore, we assessed the effects of music on anxiety and satisfaction in elderly outpatients undergoing cataract surgery using monitored anaesthetic care and retrobulbar block.

\section{Methods}

Institutional Ethics approval was obtained from the Research on Human Subjects Committee of the Toronto Hospital. Patients scheduled for elective cataract extraction in the Ambulatory Surgery Unit at the Toronto Western Division of the Toronto Hospital were studied after informed consent was obtained. Those patients who were taking sedative or psychotropic drugs, or who suffered hearing impairment, were excluded.

Randomization was by patients selecting from a bag one of four different tapes in a blinded fashion. The tapes were played via headphones and an audiocassette player:

Group 1: Relaxing Suggestions: relaxing, calming suggestions repeated at regular intervals of one to two minutes. Suggestions were simple phrases "Operation is going well. Everything is going smoothly."

Group 2: White Noise: Level of normal noise in a quiet environment.

Group 3: OR noise: A tape which contained the playback of a previously recorded cataract operation.
Group 4: Relaxing Music: Classical music accompanied by soothing sounds of nature.

No overhead music was allowed in the operating room during the study. Following the application of standard monitors, ECG and non-invasive arterial blood pressure cuff, and the establishment of an iv catheter, the headphones were adjusted to comfort and a satisfactory volume level of the tape by the research assistant. Patients were sedated by the anaesthetist blinded to the tape randomization. Intravenous 1-2 $\mu \mathrm{g} \cdot \mathrm{kg}^{-1}$ fentanyl or 5-10 $\mu \mathrm{g} \cdot \mathrm{kg}^{-1}$ alfentanil and $7-15 \mu \mathrm{g} \cdot \mathrm{kg}^{-1}$ midazolam were used. Two or three minutes after in sedation, retrobulbar block was performed by the ophthalmologist. To assess recall during the time of insertion of the retrobulbar block, patients were shown a picture prior to the retrobulbar block, and asked to recall it later.

Vital signs (systolic blood pressure [SBP], diastolic blood pressure $[\mathrm{DBP}]$, heart rate $[\mathrm{HR}]$, and respiratory rate $[R R]$ ) were recorded before and after the retrobulbar block, and at $15 \mathrm{~min}$ intervals thereafter until completion of the procedure by the research assistant. Anxiety was assessed using the State-Trait Anxiety Inventory (STAI) (13), which was conducted preoperatively and postoperatively, and by a visual analogue scale (VAS) postoperatively by the research assistant. The State-Trait Anxiety Inventory Test provided two measures: one for trait anxiety and one for state anxiety. The same test was used to obtain two different anxiety measures, the trait anxiety was not expected to vary with time and the state anxiety was expected to vary with time.

Patient satisfaction was evaluated using a postoperative questionnaire using Yes/No responses (Appendix). Questions asking patients about satisfaction with the operative experience, whether they were nervous during the surgery, satisfaction with the tape, whether the tape relaxed them, whether the noise in the operating room bothered them and whether they would want the tape again were used (Appendix). The ophthalmologists who were blinded to the tape randomization were asked whether they were satisfied with the anaesthetic technique using VAS, $0 \mathrm{~mm}$ extremely dissatisfied, $100 \mathrm{~mm}$ extremely satisfied.

Data were entered into database III plus program and analyzed using SAS statistical package (version 6.08 for windows). Between group differences were assessed using ANOVA for continuous variables or Chi-Square test for categorical variables, where appropriate. Where the analysis of variance detected significance, Tukey's procedure for multiple comparisons was used to identify differences between pairs. Differences within and between groups over time 
were analyzed using ANCOVA for STAI and multiple analysis of variance for vital signs. A $P$ value of $<0.05$ was considered significant. Bonferroni's correction was applied where appropriate.

\section{Results}

A total of 121 patients were enrolled in the study: relaxing suggestion-30; white noise-29; operating room noise- 30 ; relaxing music-32. There were no differences in age, sex, distribution of ASA physical status, weight, or doses of opioids or sedative drugs received (Table I). There was no difference in recollection of the picture shown prior to the retrobulbar block.

Vital signs (SBP, DBP, HR, RR) for the four groups over time are shown in Figures 1 to 4. Although differences did arise within groups over time (see asterisks in figures), there were no differences in vital signs among groups at any time except for systolic blood pressure. The systolic blood pressure increased at period $l$ in the relaxing suggestion, white noise and relaxing music groups (but not in the operating room noise group), and decreased at periods 2 and 3 only in the operating room noise group $(P<0.05)$.

APPENDIX Postoperative Patient Questionnaire (Visual Analogue Scale)

\section{Patient:}

Were you SATISFIED with the whole operative experience?

$\begin{array}{ll}\text { extremely } & \text { extremely } \\ \text { dissatisfied } & \text { satisfied }\end{array}$

Did you feel NERVOUS or ANXIOUS during the surgery?

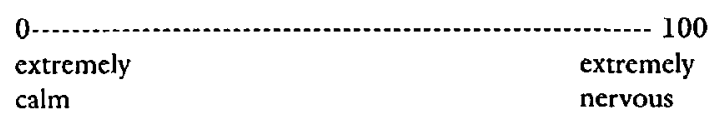

Were you SATISFIED with the tape you listened to?

$\begin{array}{ll}\text { extremely } & \\ \text { dissatisfied } & \begin{array}{l}\text { extremely } \\ \text { satisfied }\end{array}\end{array}$

Did you find the tape RELAXED you?

$\begin{array}{ll}\text { extremely } & \text { extremely } \\ \text { not relaxed } & \begin{array}{l}100 \\ \text { relaxed }\end{array}\end{array}$

Did the noise in the operating room BOTHER you?

$\begin{array}{ll}\text { extremely } & \text { extremely } \\ \text { pleasant } & \text { bothersome }\end{array}$

Would you WANT the tape AGAIN?

Yes/No

Ophthalmologist:

Were you satisfied with the anaesthetic technique used?

$\begin{array}{ll}\text { extremely } & \text { extremely } \\ \text { dissatisfied } & \text { satisfied }\end{array}$

The STAI scores were not different among groups before or after surgery (Table II). There was a reduction in state anxiety in the relaxing suggestions and relaxing music groups after surgery versus before surgery $(P<0.05$, paired $t$ test $)$.

Results of the postoperative patient questionnaire are summarized in Table III. Patients who received relaxing music were more satisfied with the operative experience and its auditory accompaniment and felt

TABLE I Patient Characteristics

\begin{tabular}{lllll}
\hline GROUP & $R S$ & $W N$ & ORN & $R M$ \\
\hline Number & 30 & 29 & 30 & 32 \\
Age (yr) & $68.5 \pm 3$ & $73.6 \pm 2$ & $68.3 \pm 2$ & $70.8 \pm 2$ \\
M:F & $12: 18$ & $12: 17$ & $12: 18$ & $8: 24$ \\
ASA 1 & 8 & 7 & 11 & 4 \\
2 & 20 & 18 & 17 & 24 \\
$\quad 3$ & 2 & 4 & 2 & 4 \\
Weight $(\mathrm{kg})$ & $64.9 \pm 2$ & $68.6 \pm 2$ & $65.7 \pm 2$ & $70.9 \pm 3$ \\
Fentanyl $(\mu \mathrm{g})$ & $54 \pm 5$ & $56 \pm 10$ & $60 \pm 4$ & $50 \pm 5$ \\
$\quad(\mathrm{n})$ & 18 & 18 & 22 & 21 \\
Alfentanil $(\mu \mathrm{g})$ & $529 \pm 54$ & $400 \pm 71$ & $550 \pm 50$ & $422 \pm 40$ \\
$\quad(\mathrm{n})$ & 12 & 9 & 5 & 8 \\
Midazolam $(\mathrm{mg})$ & $1.1 \pm 0.1$ & $1.1 \pm 0.1$ & $1.0 \pm 0.1$ & $0.9 \pm 0.1$ \\
$(\mathrm{n})$ & 30 & 28 & 29 & 31 \\
\hline
\end{tabular}

$\mathrm{RS}=$ relaxing suggestions. $\mathrm{WN}=$ white noise. $\mathrm{ORN}=\mathrm{OR}$ noise. $\mathrm{RM}=$ relaxing music.

TABLE II STAI Scores

\begin{tabular}{llllll}
\hline Group & $R S$ & $W N$ & $O R N$ & $M$ & $P^{*}$ \\
\hline n & 30 & 29 & 30 & 32 & \\
Trait Anxiety & $26.7 \pm 1$ & $25.2 \pm 2$ & $27.5 \pm 2$ & $29.6 \pm 2$ & $>0.05$ \\
Pre State Anxiety & $27.5 \pm 2$ & $25.3 \pm 1$ & $26.5 \pm 1$ & $27.9 \pm 2$ & $>0.05$ \\
Post StateAnxiety & $24.5 \pm 1$ & $23.5 \pm 1$ & $23.7 \pm 1$ & $24.1 \pm 1$ & $>0.05$ \\
P\# & 0.02 & 0.09 & 0.08 & 0.01 & \\
\hline
\end{tabular}

$\mathrm{RS}=$ relaxing suggestions. $\mathrm{WN}=$ white noise. $\mathrm{ORN}=\mathrm{OR}$ noise $\mathrm{RM}=$ relaxing music.

$P \star v a l u e s$ represent between group comparisons using ANOVA.

$P \#$ values represent within group comparisons for state anxiety using paired $t$ test.

TABLE III Questionnaire Scores (VAS)

\begin{tabular}{llllll}
\hline Group & $R S$ & $W N$ & ORN & $M$ & $P$ \\
\hline Operative & & & & & \\
Experience & $\mathbf{8 5 . 0 \pm 3}$ & $\mathbf{8 2 . 6 \pm 3}$ & $82.2 \pm 2$ & $92.0 \pm 2$ & $0.0172^{\mathrm{a}}$ \\
Nervous & $17.2 \pm 3$ & $14.8 \pm 3$ & $21.4 \pm 3$ & $18.6 \pm 4$ & $>0.05$ \\
Satisfied & $54.4 \pm 4$ & $43.4 \pm 4$ & $49.3 \pm 4$ & $84.8 \pm 2$ & $0.0001^{\mathrm{b}}$ \\
Relaxed & $56.1 \pm 4$ & $39.7 \pm 3$ & $45.4 \pm 4$ & $84.4 \pm 2$ & $0.0001^{\mathrm{c}}$ \\
Bother & $11.7 \pm 1$ & $12.7 \pm 3$ & $11.8 \pm 3$ & $6.7 \pm 1$ & $0.0909^{\mathrm{d}}$ \\
Want Again $(\mathrm{Y}: \mathrm{N})$ & $20: 10$ & $6: 23$ & $7: 23$ & $31: 1$ & $0.0001^{\mathrm{c}}$ \\
Surgeon & $88.2 \pm 1$ & $80.9 \pm 2$ & $84.1 \pm 1$ & $92.7 \pm 2$ & $0.0001^{\mathrm{f}}$ \\
\hline
\end{tabular}

$R S=$ relaxing suggestions. $W N=$ white noise. $O R N=O R$ noise

$\mathrm{RM}=$ relaxing music.

$a, b, c, f$ Groups I, II and III $<$ IV

d II vs IV significant at 95\% (Fisher PLSD)

c Chi-square 


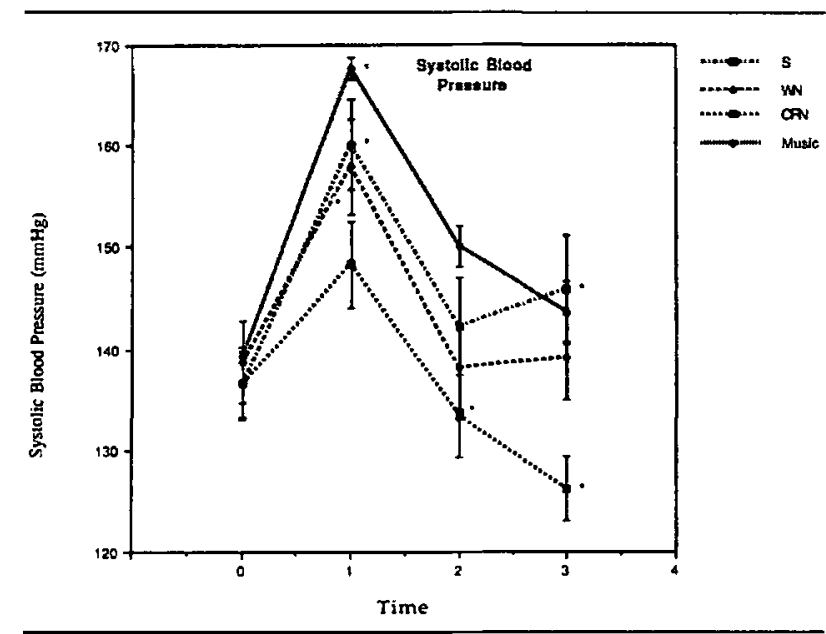

FIGURE 1 Systolic blood pressure ps time 0 (pre-retrobulbar block), time 1 (immediately post retrobulbar block), time 2 (15 min post retrobulbar block), time 3 ( 30 min post retrobulbar block), for all patients. Data are mean+SEM. Asterisks (*) indicate a within group difference compared with time $0(P<0.05)$. RS=relaxing suggestions. $\mathrm{WN}=$ white noise. $\mathrm{ORN}=\mathrm{OR}$ noise. $\mathrm{RM}=$ relaxing music.

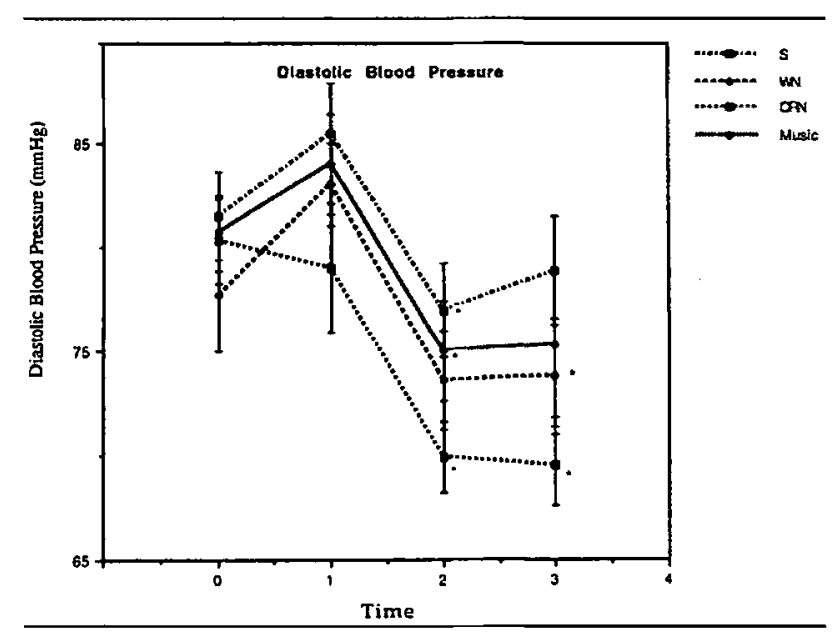

FIGURE 2 Diastolic blood pressure os time 0 (pre-retrobulbar block), time 1 (immediately post retrobulbar block), time 2 ( $15 \mathrm{~min}$ post retrobulbar block), time 3 ( $30 \mathrm{~min}$ post retrobulbar block), for all patients. Data are mean \pm SEM. Asterisks ( $\left.{ }^{*}\right)$ indicate a within group difference compared with time $0(P<0.05)$. RS=relaxing suggestions. $\mathrm{WN}=$ white noise. $\mathrm{ORN}=\mathrm{OR}$ noise. $\mathrm{RM}=$ relaxing music.

more relaxed than patients in any of the other three groups (relaxing suggestions more than white noise or OR noise). Similarly, surgeons were more satisfied with patients in the music group than patients hearing the relaxing suggestions, white noise or OR noise.

The majority of patients experiencing relaxing music indicated they would prefer this modality again (31:1), more so than patients hearing relaxing suggestions $(20: 10)$. Only $20.6 \%(6 / 29)$ in the white noise group and $23.3 \%(7 / 30)$ in the operating room noise group would prefer this modality again.

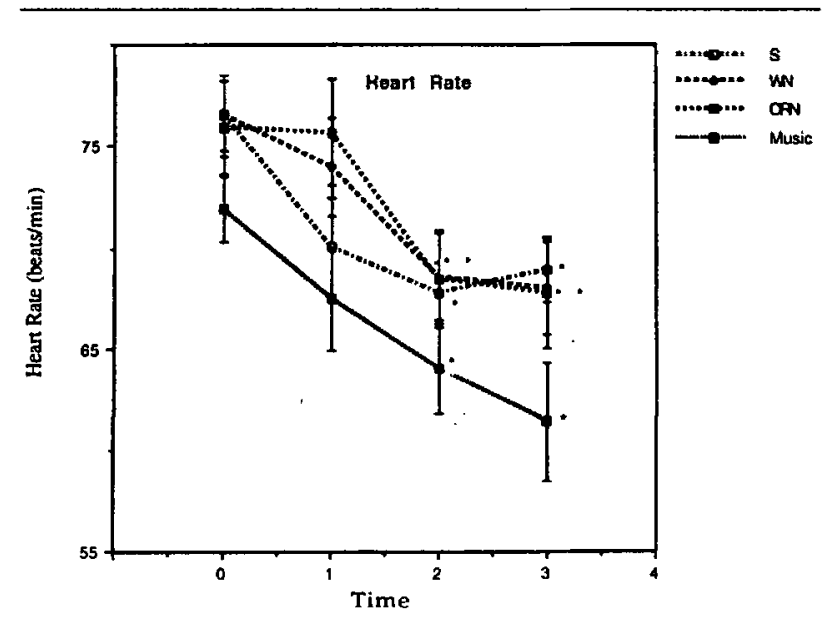

FIGURE 3 Heart rate vs time 0 (pre-retrobulbar block), time 1 (immediately post retrobulbar block), time 2 ( $15 \mathrm{~min}$ post retrobulbar block), time 3 (30 min post retrobulbar block), for all patients. Data are mean \pm SEM. Asterisks (*) indicate a within group difference compared with time $0(P<0.05)$. RS=relaxing suggestions. $\mathrm{WN}=$ white noise. $\mathrm{ORN}=\mathrm{OR}$ noise. $\mathrm{RM}=$ =relaxing music.

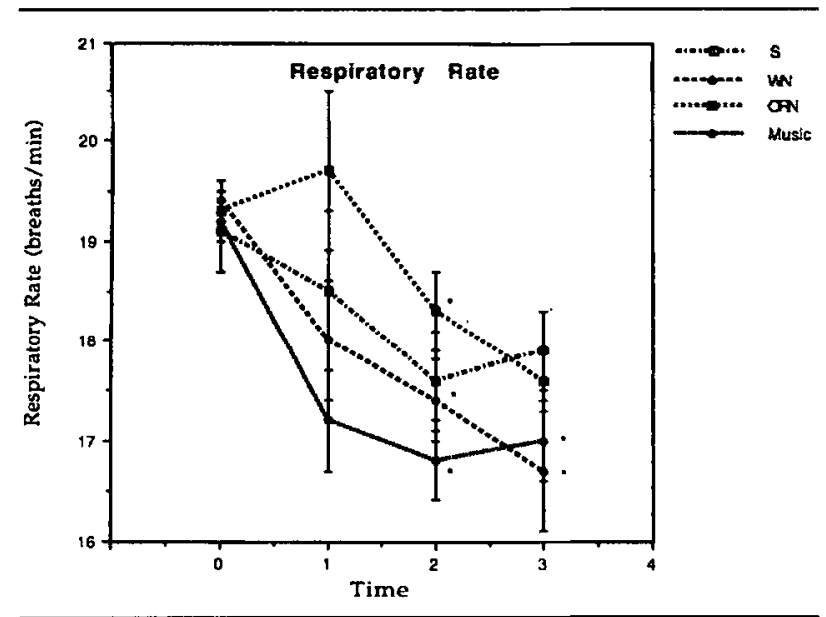

FIGURE 4 Respiratory rate $v$ s time 0 (pre-retrobulbar block), time 1 (immediately post retrobulbar block), time 2 ( $15 \mathrm{~min}$ post retrobulbar block), time 3 ( 30 min post retrobulbar block), for all patients. Data are mean \pm SEM. Asterisks $\left(^{*}\right)$ indicate a within group difference compared with time $0(P<0.05)$. $\mathrm{RS}=$ relaxing suggestions. $\mathrm{WN}=$ white noise. $\mathrm{ORN}=\mathrm{OR}$ noise. $\mathrm{RM}=$ relaxing music.

Only patients hearing white noise, compared with those receiving relaxing music, found their auditory choice bothersome (12.7 \pm 3 [group 2] ps $6.7 \pm 1$ [group 4], significant at $95 \%$ ), and when specifically asked about nervousness, there were no differences in scores among any of the groups.

\section{Discussion}

Our study showed that music and relaxing suggestions were consistently superior to white noise or operating room noise in improving patient and surgeon satisfac- 
tion. We were unable to show objective evidence of reduction in anxiety in any of the groups of patients studied. There were no differences between or within groups over time in STAI or vital signs. Following the retrobulbar block, an unexpected increase in systolic blood pressure occurred in the relaxing suggestion, white noise and relaxing music groups, but not in the operating room noise group, in which the systolic blood pressure actually declined over time.

Opinion whether music is beneficial in the operating room is divided. Even noise levels of standard procedures, such as opening a package of rubber gloves, can be very loud, approaching 90 decibels, which is equivalent to the noise of a motorcycle at 8 metres. ${ }^{15}$ There has been increasing concern over the use of loud music played in the $O R$, since it may contribute to the overall level of background noise and impair effective communication among members of the surgical team. In many cases, standards of electrical safety for portable music equipment are ignored. ${ }^{6}$ Further, opinion varies on what kind of music is appropriate, ${ }^{7}$ at what volume the music should be played, and for how long. ${ }^{18}$

Others argue that music is a useful tool for alleviating anxiety in patients before, during and after surgery, and in various other stressful clinical circumstances. In two recent studies of patients in coronary care units, music did not alter physiological variables such as heart rate, blood pressure or respiratory rate, nor did it reduce anxiety scores when compared with groups receiving either white noise or no music. ${ }^{19,} 20$ In a study of $\mathbf{3 3}$ outpatient arthroscopic procedures, patients received sedative, music or no music. Only respiratory rate was reduced in the sedative group after $20 \mathrm{~min}$, with both sedative and music groups showing a reduction in anxiety test scores. ${ }^{21}$ Reductions in blood pressure were noted, with a shift in mood toward a more relaxed state in plastic surgery patients that listened to music. ${ }^{5}$ Patients in the music group scored lower in state anxiety postoperatively, than did their preoperative values in patients undergoing arthroscopic surgery. ${ }^{6}$

In patients undergoing orthopaedic or plastic surgery with regional anaesthesia, patients listening to music had fewer preoperative and intraoperative demands for sedatives. ${ }^{7}$ During Caesarean section under epidural anaesthesia in 126 parturients, $75 \%$ found music to be "very beneficial." In patients undergoing laceration repair in an emergency department, pain scores were less in the group that received music, than in the control group. The anxiety scores were not different between groups after the procedure. Our results are similar to previous studies in that there was a subjective improvement in anxiety with music but objective evidence from physiological changes or an anxiety score that was lacking.

In this study, a standardized dose of fentanyl or alfentanil and midazolam was given to the study patient. There was no attempt to determine the need for sedative medication as a function of the auditory stimuli presented. Therefore, the standardized anaesthetic may have obliterated the possible differences in anxiety among the four groups of patients. Although the anaesthetist giving the anaesthetic and the ophthalmologist were blinded to the type of auditory tape, the research assistant was not blinded to the type of auditory tape. This can introduce possible bias in the study.

In summary, elderly patients undergoing cataract surgery with retrobulbar block were more satisfied with their experience if they heard relaxing music rather than relaxing suggestions or white noise or operating room noise. The type of auditory stimuli to which the patients were exposed did not influence the level of anxiety. In an era where patient satisfaction seems to be a paramount goal, ${ }^{23}$ it would appear that music plays a role in enhancing this satisfaction, and is a useful tool in outpatients undergoing peripheral procedures with monitored anaesthetic care.

\section{Acknowledgements}

The authors wish to thank Dr. Joseph Lena for assistance in data collection, and $\mathrm{Mr}$ Anthony Ayiomamitis M.Sc. for his expert statistical advice.

\section{References}

1 Arellano $R$, Cruise C, Chung F. Timing of the anesthetist's preoperative outpatient interview. Anesth Analg 1989; 68: 645-8.

2 Eckenhoff JE, Helrich $M$. Study of narcotics and sedatives for use in preanesthetic medication. JAMA 1958; 167: 415-22.

3 Pbilip BK. Supplemental medication for ambulatory procedures under regional anesthesia. Anesth Analg 1985; 64: 1117-25.

4 Hodge B, Thompson JF. Noise pollution in the operating theatre. Lancet $1990 ; 335: 891-4$.

5 Updike PA, Charles DM. Music Rx: physiological and emotional responses to taped music programs of preoperative patients awaiting plastic surgery. Ann Plast Surg 1987; 19: 29-33.

6 Moss VA. Music and the surgical patient. Association of Operating Room Nurses Journal 1988; 48: 64-9.

7 Walther-Larsen S, Diemar V, Valentin N. Music during regional anesthesia. Reg Anesth 1988; 13: 69-71.

8 Naidu KRC. Music sedation for local analgesia (Letter). Anaesthesia 1982; 37: 354. 
9 Goroszeniuk T, Morgan BM. Music during epidural Caesarean section. Practitioner 1984; 228: 441-3.

10 Apfelbaum JL, Kallar SK, Wetchler BV. Adult and geriatric patients. In: Wetchler BV (Ed.). Anesthesia for Ambulatory Surgery, 2nd ed. Philadelphia: JB Lippincott, 1991: 197-307.

11 Miller RD. Anesthesia for the elderly. In: Miller RD (Ed.). Anesthesia, 2nd ed. New York: Churchill Livingstone Inc., 1986: 1801-18.

12 Greenblatt DJ, Sellers EM, Shader RI. Drug disposition in old age. N Engl J Med 1982; 306: 1081-8.

13 Spielberger $C D$. Manual for the state-trait anxiety inventory (Form Y). Palo Alto: Consulting Psychologists Press, Inc, 1983.

14 Stoudenmire J. A comparison of muscle relaxation training and music in the reduction of state and trait anxiety. J Clin Psychol 1975; 31: 490-2.

15 Shapiro $R A$, Berland $T$. Noise in the operating room. N Engl J Med 1972; 287: 1236-8.

16 Schneider AJL, Biebuyck JF. Music in the operating-room (Letter). Lancet 1990; 335: 1407.

17 Ayre P. The tempest (Editorial). Anaesthesia 1980; 35: 233-4.

18 Condon HA. Music in hospitals (Letter). Anaesthesia $1980 ; 35: 716$.

19 Zimmerman LM, Pierson MA, Marker J. Effects of music on patient anxiety in coronary care units. Heart Lung 1988; 17: 560-6.

20 Davis-Rollans C, Cunningham SG. Physiologic responses of coronary care patients to selected music. Heart Lung 1987; 16: 370-8.

21 Kaempf $G$, Amodei $M E$. The effect of music on anxiety. Association of Operating Room Nurses Journal 1989; 50: 112-8.

22 Menegazzi J], Paris PM, Kersteen CH, Flynn B, Trautman DE. A randomized, controlled trial of the use of music during laceration repair. Ann Emerg Med 1991; 20: 348-50.

23 Clemenhagen C. Patient satisfaction: the power of an untapped resource. Can Med Assoc J 1994; 150: 1771-2. 